\title{
The hardness of five acrylic artificial teeth brands marketed in Bandung city
}

\author{
Hasna Dziab*, Zulia Hasratiningsih**, Erna Kurnikasari* \\ *Department of Prosthodontics Faculty of Dentistry Universitas Padjadjaran \\ ${ }^{* *}$ Department of Dental Material Science and Technology \\ Faculty of Dentistry Universitas Padjadjaran
}

\begin{abstract}
The acrylic artificial teeth are still among the most frequently used artificial teeth. Some commercial brands marketed in Bandung claim that their products have met the existing standards. However, those brands do not give any mechanical property data, including data on hardness. The ADA specification standard no. 15 requires a hardness of minimum $15.00 \mathrm{KHN}$ for acrylic artificial teeth. The aim of this study is to find out which acrylic artificial teeth actually have a standardized hardness value. The study is an analytical descriptive study, which is performed on 5 brands of acrylic artifical teeth marketed in Bandung. From each brand, 4 teeth were sampled and receive 10 indentation spots on the upper and lower surfaces. It is concluded that the five acrylic artificial teeth brands have met the ADA specification standard no. 15 and there are differences in hardness values among the five brands.
\end{abstract}

Key words: Acrylic artificial teeth, ADA specification no. 15 hardness

\section{INTRODUCTION}

Plastic teeth (acrylic artificial teeth) have been well known since 1930 and are used by most dentists. According to Anusavice ${ }^{1}$, more than $60 \%$ of the ready made artificial teeth sold in the United States are made from acrylic resin or acrylic vinyl resin.

These acrylic artificial teeth have several advantages, i.e. light, easy to grind and polish and have self-adjusting and self-balancing properties. The disadvantages of these teeth are the reduced strength and low resistance towards abrasion that they can change dental occlusion and the vertical dimension. ${ }^{2-5}$

The acrylic artificial teeth that meet ADA specification no.15 standard are made from polyacrylic, polyacrylic filler, polyvinyl ester copolimer or a mixture of those materials. The chemical bond between the artificial teeth and the base (bond strength) is $315 \mathrm{~kg} / \mathrm{cm}^{2}$ (31 MPa) with a hardness of no less than $15.00 \mathrm{~kg} / \mathrm{mm}^{2}(\mathrm{KHN})$. The tooth should not experience discoloration or form change when it is heated in $100{ }^{\circ} \mathrm{C}$ water for 3 hours. ${ }^{4-6}$

Hardness is an important property in the dentistry field. This is obvious from the fact that a hardness test is included for various types of dental materials as a requirement to gain the ADA specification. ${ }^{1,7}$

Hardness can be defined as the resistance of solid materials towards infiltration or ability 
to resist scratch and indentation both by knife or blunt tools. ${ }^{5,8}$ Hardness is a property that is used to estimate the wear resistance of a material and ability to grind off the opposite tooth structure. ${ }^{1}$

The acrylic artificial teeth are used based on several consideration including the availability, esthetic and affordable price. These have encourage the dental suppliers in Bandung city to market various brands of acrylic artificial teeth. There are several brands who claim that their brand has met the standard and there are some who do not make such claim. However, both do not include mechanical property data (hardness). In Indonesia, there is no testing institution yet that tests the quality of dental materials marketed in Indonesia.

Many patients come to dentist private practices or clinics wearing acrylic artificial teeth that are worn, malformed or broken. Based on the description above, the author is interested to test one of the mechanical properties of the acrylic artificial tooth, i.e. the hardness of the acrylic artificial teeth as compared to the ADA specification no. 15 standard.

\section{METHOD AND MATERIAL}

The study is an analytical descriptive study. This type of study is chosen to give a description on a situation in an objective manner. ${ }^{9}$ The study sample is collected from 5 acrylic artificial teeth brands that are most frequently found in Bandung city market. Four artificial teeth were selected from each brand as sample. Each tooth was then grinded flat with a thickness of $2.5 \pm 0.5 \mathrm{~mm}$ and was invested in a clear resin. ${ }^{6,10}$

The instruments needed for this study is the Buehler Micromet II Knoop Hardness instrument, polisher grinder, mixing jar, handpiece, micromotor, fraser, $10 \mathrm{ml}$ measuring glass, cement spatula, tweezers, sand paper, sextant, and molding tray. The materials used in this study are the five acrylic artificial teeth brands, clear resin, Vaseline, polishing chalk, distillated water, and catalyst.

The sample is made using the following steps: grind the incisal/occlusal and cervical parts of the artificial acrylic tooth using micromotor, handpiece and fraser that the upper and lower surfaces of the artificial acrylic tooth becomes

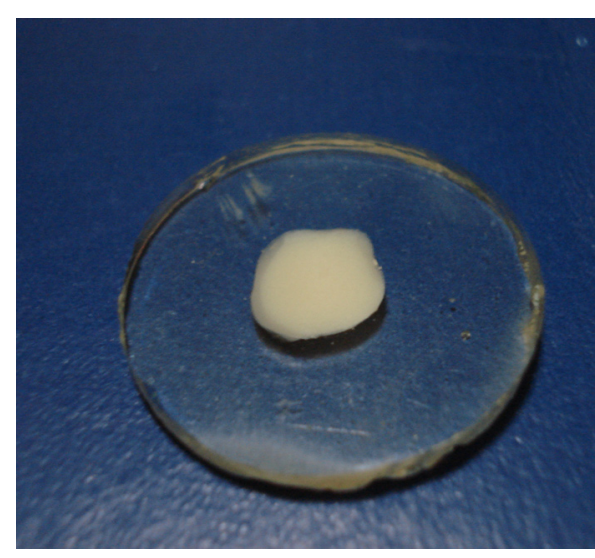

Figure 1. Study Sample.

flat and parallel with a thickness of $2.5 \pm 0.5 \mathrm{~mm} .6 .10$ Invest the ground artificial acrylic tooth in clear resin, wait until dry and then make the surface smooth using the sand paper and polish the sample using polishing chalk until the surface is smooth and shiny.

The hardness value test was performed using Knoop micro hardness testing instrument using the following steps: Place the Knoop micro hardness tester in a stable position. Put the test sample in the instrument in such a way that the sample surface is perpendicular with the $90^{\circ}$ axis and the loading axis of the testing instrument. ${ }^{11}$ Perform loading or pressing using 100 gram of weight for 20 seconds. ${ }^{6,10}$ Measure the longest diagonal of the pressing mark using a microscope. Note the micro Knoop hardness value that is directly displayed in the monitor. ${ }^{11}$ Perform 10 times testing for each sample and then calculate the average value to get one harness value for one artificial acrylic tooth. ${ }^{6}$

To discover which acrylic artificial teeth that have a hardness value that meets ADA specification no.15 data the study data were analyzed using $F$ test statistic of one way ANAVA to see whether there is a different between the hardness value average of the acrylic artificial tooth from different brand and ADA specification no.15. If there is a different, then Dunnett test is performed after the ANAVA test.

\section{RESULTS}

Table 1 lists the average value of acrylic artificial tooth hardness after a test using Buehler Micromet II Knoop Hardness testing instrument. 
Table 1. Average value of acrylic artificial tooth hardness (KHN)

\begin{tabular}{cccccc}
\hline \multirow{2}{*}{ Sample } & \multicolumn{5}{c}{ Acrylic artificial tooth brand } \\
\cline { 2 - 6 } & A & B & C & D & E \\
\hline I & 16.80 & 16.57 & 19.05 & 17.58 & 18.00 \\
II & 17.48 & 17.12 & 18.44 & 17.53 & 17.10 \\
III & 17.82 & 17.52 & 17.87 & 17.48 & 16.96 \\
IV & 19.71 & 16.81 & 17.58 & 17.86 & 15.92 \\
\hline
\end{tabular}

Table 2. One-way ANAVA for acrylic artificial tooth hardness value

\begin{tabular}{lcccccc}
\hline Variation source & $\begin{array}{c}\text { Degree of } \\
\text { freedom }\end{array}$ & $\begin{array}{c}\text { Square } \\
\text { total }\end{array}$ & $\begin{array}{c}\text { Median } \\
\text { square }\end{array}$ & $\begin{array}{c}F \\
\text { calculation }\end{array}$ & F 0.05 & Note \\
\hline Among groups & 5 & 26.80 & 5.36 & 11.10 & 2.77 & Significantly different \\
In the group & 18 & 8.70 & 0.48 & & & \\
Total & 23 & 35.50 & & & & \\
\hline
\end{tabular}

Table 3. Dunnett test for comparing the hardness values of various brand acrylic artificial teeth

\begin{tabular}{ccccc}
\hline $\begin{array}{c}\text { (I) Acrylic artificial } \\
\text { tooth brand }\end{array}$ & $\begin{array}{c}\text { (J) Acrylic artificial } \\
\text { tooth standard }\end{array}$ & $\begin{array}{c}\text { Average difference } \\
(\mathbf{I}-\mathrm{J})\end{array}$ & Sign & Note \\
\hline A & Standard & 2.95 & 0.00 & Significantly different \\
B & Standard & 2.01 & 0.00 & Significantly different \\
C & Standard & 3.24 & 0.00 & Significantly different \\
D & Standard & 2.61 & 0.00 & Significantly different \\
E & Standard & 2.00 & 0.00 & Significantly different \\
\hline
\end{tabular}

Based on the ANAVA table above (Tab. 2) it is revealed that $F$ calculation is 11.10 which is bigger than $\mathrm{F} 0.05 ; 5 ; 18$. It means that there is a significant difference between the average values of the acrylic artificial tooth hardness from the five brands and the standard. From the Dunnet test table in Table 3, the comparison of the hardness value of the acrylic artificial tooth from brand $A, B, C, D$, and $E$ to the standard shows that the acrylic artificial teeth of the five brands have a higher average hardness value compared to the ADA standard.

\section{DISCUSSION}

The five acrylic artificial teeth brands have different average hardness value and all five brands have a hardness value of more than 15.00 $\mathrm{KHN}$ which means that the five acrylic artificial teeth brands have met the ADA specification standard no. 15. The acrylic artificial tooth brand that has the lowest average hardness value is brand $E$ with a hardness value of $17.00 \mathrm{~kg} / \mathrm{mm}^{2}$
(KHN) while the brand with the highest hardness value is brand $C$ with a hardness value of 18.24 $\mathrm{kg} / \mathrm{mm}^{2}(\mathrm{KHN})$. According to Craig and Powers ${ }^{5}$, the acrylic artificial tooth hardness value is $18-20$ $\mathrm{kg} / \mathrm{mm}^{2}$. In this case, the brand that meets this standard is brand $\mathrm{C}$, while the others do not meet this standard.

Although the five brands of acrylic artificial teeth in this study have met the ADA specification no. 15 standards, the occlusal and cervical parts of the acrylic artificial tooth have been cut. The occlusal part contain many of the crown linking area compared to other parts of the artificial tooth so that when a hardness test is performed to the occlusal part it is assumed that the value will be higher than the value gained in this study. The selection of artificial teeth should also consider the hardness value of the opposing teeth even though those five brands of acrylic artificial tooth brands have met the ADA specification standard no. 15. If the hardness of the opposing teeth is much bigger than the value of this artificial teeth, the artificial teeth will still be worn out fast. 


\section{CONCLUSION}

The conclusion from this study is as follow: All five brands of acrylic artificial teeth have a hardness value of more than $15.00 \mathrm{KHN}$ which means that the five bands have already met the ADA specification no. 15 standard. There are differences in the hardness value of the five acrylic artificial tooth brands.

\section{REFERENCES}

1. Anusavice KJ. Phillips science of dental materials. $11^{\text {th }}$ ed. Philadelphia: Saunders Co; 2003. p. 75-101,754-5.

2. Zarb GA, Bolender CL, Hickey JC, Carlsson GE. Boucher's prosthodontic treatment for edentulous patients. $10^{\text {th }}$ ed. St Louis: Mosby Inc.; 1990. p. 295-300, 486-9.

3. Combe. Notes on dental material. $6^{\text {th }}$ ed. Edinburg: Churchill Livingstone; 1992. p. 712, 174-5.

4. Craig RG. Restorative dental materials $9^{\text {th }}$ ed.
St Louis: Mosby Co; 1993. p. 86-98, 502-38.

5. Powers JM. Restorative dental materials. $11^{\text {th }}$ ed. St Louis: Mosby Co; 2002. p. 102-16, 6725.

6. American Dental Association. Guide to dental materials and devices. Chicago: Illinois; 1974. p. 102-5, 212-4.

7. Phillips RW. Science of dental materials. $7^{\text {th }}$ ed. Philadelphia: W.B. Saunders Co; 1973. p. 42-7, 215.

8. Moore BK. Elements of dental materials for dental hygienists and dental assistants. USA: WB Saunders Co; 1994. p. 29-31.

9. Notoatmodjo S. Metodologi penelitian kesehatan. Revised ed. Jakarta: P.T. Rineka Cipta; 2002. p. 138-44.

10. Campanha NH, Pavarina AC, Vergani CE, Machado AL. Effect of microwave sterilization and water storage on the vickers hardness of acrylic resin denture teeth. J Prosthet Dent 2005;93(4):483-7.

11. JIS handbook plastics. Japan: JIS; 1991. p. 593-7, 2439-51. 